\title{
Mangrove ecosystem
}

Nibedita Mukherjee, William J. Sutherland, Md Nabiul I. Khan, Uta Berger, Nele Schmitz, Farid Dahdouh-Guebas, Nico Koedam

\section{Source}

Nibedita Mukherjee, William J. Sutherland, Md Nabiul I. Khan, Uta Berger, Nele Schmitz, Farid Dahdouh-Guebas. (2014). Using expert knowledge and modeling to define mangrove composition, functioning, and threats and estimate time frame for recovery. EcolEvol. doi:10.1002/ece3.1085.

Mang roves are woody plants that grow normally in tropical and subtropical latitudes along the land-sea interface, bays, estuaries, lagoons, and backwaters. These plants and their associated org anisms constitute the "mangrove forest community" or "mangal". The mangal and its associated abiotic factors constitute the "mangrove ecosystem". 